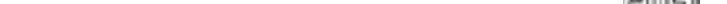





\section{Mitã kambyryru jere - notas sobre uma doença de infância entre os Kaiowá e Guarani}

Nádia Heusi Silveira*

Desde que comecei a visitar Téyikue, a Terra Indígena Caarapó $^{1}$, em 2004, a fim de conhecer um pouco a realidade associada à desnutrição nas crianças guarani, soube da existência dessa enfermidade conhecida como "coaio virado". Logo de início tive oportunidade de visitar, em companhia de agentes indígenas de saúde, algumas casas em que havia crianças com baixo peso, para conversar com as mães sobre o que poderia estar causando o emagrecimento das crianças. Sistematicamente, elas se referiram ao coaio virado ou coaiado virado - kambyryru jere em guarani - e explicaram que esse tipo de doença não pode ser tratado pelos médicos, que não conseguem diagnosticá-la. Quando a criança adoece, as mães buscam benzedores ou rezadores, atividade xamanística desempenhada por mulheres e homens kaiowá e guarani, pois apenas eles conhecem a forma de "arrumar" o coaio virado. A partir de então, acompanhei alguns casos e recolhi outras informações sobre esse problema de saúde, basicamente com as mulheres, quando a ocasião propiciou o assunto.

As mães explicaram que a enfermidade é desencadeada a partir de um movimento brusco da criança, por exemplo, uma queda. Ou também pelo fato de alguém pegar a criança de mau jeito, como certas brincadeiras em que a criança é balançada repentinamente ou jogada para o alto. Até mesmo quando a mãe transfere seu bebê de um peito para o outro, ao amamentar, se o faz de maneira abrupta, ou gira a criança de forma inadequada, poderá provocar o coaio virado.

Os principais sintomas do coaio virado são diarréia com odor característico e geralmente intensa, febre e vômitos. A criança fica triste e não quer comer. O movimento brusco provoca três fenômenos interligados: a criança se assusta; o leite estraga, "coagula na costela" e os ossos saem do lugar. A doença é grave e pode levar à morte. A maioria das pessoas com quem conversei

\footnotetext{
* Integrante do Programa Kaiowá-Guarani, no Núcleo de Estudos e Pesquisas das Populações Indígenas (NEPPI/UCDB). Doutoranda em antropologia social na Universidade Federal de Santa Catarina (PPGAS/ UFSC). nheusi@yahoo.com.br
} 
ressaltou que não se pode demorar em buscar tratamento, três ou quatro dias de espera já é demais, tendo em vista a evolução rápida dos sintomas.

Vale dizer que existem dois tipos de coaio virado. Quando os ossos se deslocam na parte inferior do corpo - o tipo mais comum - a criança apresenta diarréia. O deslocamento dos ossos nos membros superiores é associado à presença de episódios de vômito, mas também pode ocorrer diarréia. Dois rezadores me disseram que esse tipo de coaio virado que afeta os braços ${ }^{2}$ é mais difícil de identificar e de tratar. Para confirmar o diagnóstico dessa forma mais comum, o curador estica as pernas da criança, colocando-as simetricamente uma ao lado da outra, e compara a posição das articulações pelo lado posterior. Se as articulações dos joelhos estiverem desalinhadas, isto é, em posição assimétrica, é sinal de coaio virado. Em geral, referiram-se a esse sinal dizendo que a criança está com uma perna mais curta que a outra. Se a criança desenvolve a forma da doença que afeta a parte superior do corpo, os braços e ombros é que são avaliados. Além disso, outro sinal característico é o surgimento de uma assimetria nos olhos da criança. De acordo com uma benzedora, um dos olhos parece mais fundo e o outro se nota inchado. A barriga fica inchada também e, às vezes, podem-se escutar roncos.

$O$ tratamento consiste essencialmente em massagens na região do abdômen. São utilizados emplastros com plantas, das quais a erva de santa maria foi a mais citada. Infusões desta ou de outras plantas são oferecidas à criança doente antes de comer, também como parte da terapia. Soube pouco sobre a preparação dos remédios, entretanto, pareceme que, além da mistura de ingredientes e da técnica de preparo, são necessárias recitações específicas ao longo do processo para potencializar sua eficácia.

O conhecimento terapêutico a respeito do coiao virado não é exclusivo de rezadores ou de rezadoras (ñanderu e ñandesy, respectivamente), encontra-se mais ou menos disseminado entre homens e mulheres mais velhos. A diferença é que um rezador se utiliza de recitações enquanto massageia a criança, ao passo que os benzedores restringem o tratamento às manipulações corporais e uso de remédios do mato, mas as duas formas de tratar são eficazes. Porém, segundo as mães, nem todo rezador sabe tratar o coaio virado. O tempo do tratamento varia de acordo com a gravidade do estado da criança, contudo, na maioria dos casos são necessários três dias consecutivos de tratamento. Após cada sessão de massagens, o abdômen é enfaixado para manter os ossos e órgãos internos alinhados na posição adequada. Quando a criança se restabelece os sinais desaparecem e ela volta a sentir vontade de comer. 
As características dessa doença de infância podem ser mais bem entendidas em relação à concepção de pessoa guarani. Quando nasce uma criança, uma alma ( $\left.\tilde{n} e^{\prime} e \ddot{)}\right)$ oriunda de outro plano cósmico é enviada pelas divindades ${ }^{3}$. Essa porção divina da pessoa está "pura" no início da vida, isto é, não foi ainda poluída ou contaminada por sentimentos negativos e desejos mundanos. É alma-palavra, a qual flui pelos ossos e se exprime na voz, nos cantos e na fala humana (Cadogan, 1997). Esse vínculo forte dos Guarani com o mundo celeste aonde vivem os deuses, traduz-se em práticas cotidianas e rituais, como também se materializa no corpo. Por intermédio do esqueleto, o corpo revela as qualidades divinas no humano: a fala e a postura ereta (Clastres, 1978). Na criança pequena, o vínculo da alma divina ao corpo é tênue, é um período de adaptação ao mundo terreno. É, portanto, um período que inspira cuidados de várias ordens, entre os quais atividades, alimentação, sentimentos e bom uso da palavra. Quando a criança se assusta, sua alma pode se afastar definitivamente. Daí é possível conceber que esse afastamento da alma provoque uma desordem percebida como assimetria na estrutura óssea.

Cabe, então, introduzir o tema da desnutrição infantil. É importante salientar que nem todos os casos de desnutrição são associados ao quadro de coaio virado pelos Guarani; não se trata de uma sobreposição dessas categorias de doença, embora exista uma associação empírica. Além disso, muitas vezes a criança com coaio virado não chega a perder peso. As agentes indígenas de saúde com quem conversei, tanto quanto alguns curadores guarani, explicam da seguinte forma: eles dizem que às vezes a criança tem coaio virado e também tem vermes. Nesses casos, o tratamento no posto de saúde não exclui as práticas terapêuticas guarani ou vice-versa. Ao contrário, as agentes de saúde podem indicar os dois tipos de tratamento, argumentando que afinal Deus (Ñanderu) age através de todos os tipos de especialistas, inspirando-os a curar os doentes. Aliás, não se trata apenas de biomedicina versus práticas tradicionais. Há também, na aldeia, várias igrejas neopentecostais que são acionadas como recurso terapêutico, em determinadas situações. Assim, o espaço da reserva indígena pode ser descrito como uma situação de intermedicalidade, conforme a definição de Greene (1998). Não existem fronteiras marcadas entre as diversas práticas terapêuticas disponíveis. Encontram-se visões heterogêneas sobre saúde, doença e cuidado, às vezes conflitivas, em constante negociação, permeadas por aspectos sociopolíticos tanto quanto cosmológicos ${ }^{4}$.

A perda de peso ou o fato de uma criança não crescer adequadamente são problemas atribuíveis a várias causas pelos Guarani, inclusive 
à fome. Para eles é óbvio que, nesses casos, o que está em jogo é, em geral, o uso abusivo de bebidas alcoólicas e/ou desagregação familiar. Dessa ótica, a desnutrição resulta de um desequilíbrio social, não somente das relações no âmbito da família nuclear, mas de uma certa fragmentação de alianças que culmina em contrastes no modo de vida entre as famílias grandes que residem na TI Caarapó. Está presente, também, uma inversão de valores entre o que seria o ideal de comportamento e as práticas cotidianas. Por exemplo, pude observar que uma das formas essenciais em que se efetiva a premissa da reciprocidade entre os Kaiowá e Guarani, a qual Melià et al (2008) denominam mborayhu, é por meio de uma contínua circulação de víveres entre as famílias aparentadas. No entanto, há situações em que determinadas famílias nucleares ficam excluídas deste circuito de trocas. A meu ver, a falha deste mecanismo, por si só, é um índice de disjunção sociopolítica. Embora não tenha elementos suficientes para uma análise aprofundada a respeito da problemática da fome em Te'yikue, tornou-se evidente que a insegurança alimentar é um fenômeno que imbrica mudanças socioculturais e entropia. Essas mudanças, de grande intensidade, envolvem as relações com o entorno social, local e global, na disputa por terras produtivas ${ }^{5}$.

Por fim, gostaria de retomar mais um aspecto dessa doença de infância. Uma vez que a criança teve coiado virado, ela se torna vulnerável e facilmente apresenta recidivas, quer dizer, os sintomas podem reaparecer ao menor descuido. Essa característica da doença está associada com um cotidiano marcado, frequentemente, por um afastamento no convívio da família nuclear. É bastante comum que os homens assumam trabalhos remunerados fora da reserva indígena, em destilarias de álcool e nas fazendas dos arredores, o que é conhecido como changa. Além disso, algumas mulheres também se engajam em trabalhos, mais frequentemente no interior da reserva, nas escolas e nos postos de saúde, ou ainda desenvolvendo serviços domésticos remunerados, os quais as fazem ausentar-se de casa por períodos mais ou menos longos.

Se partirmos da interpretação da medicina guarani proposta por Cadogan (2003), é viável entender o coiado virado como um processo de doença que aponta para um déficit na esfera sociológica. Cadogan classifica a origem das doenças entre aquelas derivadas de um comportamento inadequado (teko achy) e as que se originam da ação maléfica (pochy) de um agente humano ou sobrenatural. Pochy não denomina a ação em si mesma, mas o sentimento que a provoca: cólera, raiva, ruindade ou velhacaria (cf. Montoya apud Cadogan, 2003). O malefício humano, a feitiçaria nesse caso, é também mediado pela manipulação de poderes 
sobrenaturais. Em suma, este esquema poderia ser entendido como um mapa que indica se o desequilíbrio é oriundo da dimensão sociológica (teko achy) ou cosmológica (pochy). Tendo em mente a descrição anterior, pode-se concluir que os Kaiowá e Guarani identificam o surgimento da enfermidade com a forma de cuidado, do comportamento dos pais e outros parentes que assumem essa tarefa em relação àquela criança. $\mathrm{O}$ que não significa absolutamente endereçar a responsabilização aos familiares já que, na maior parte das vezes, as circunstâncias que impelem à reconfiguração das relações no âmbito das famílias grandes estão para além da agência individual, pois abarcam uma ampla rede de relações pluriétnicas. Por fim, acredito que a correspondência esquematizada acima seja válida para refletir sobre o contexto em questão, pois o fato de não haverem mais casas de reza na TI Caarapó pode ser considerado, erroneamente, como enfraquecimento do xamanismo guarani. No entanto, aí o cotidiano é permeado pela referência contínua ao conhecimento xamânico, o que, espero, esta descrição do coaio virado tenha permitido vislumbrar.

\section{Notas}

${ }^{1}$ Trata-se de uma Reserva Indígena demarcada em 1924 pelo Serviço de Proteção aos Índios, localizada na região da Grande Dourados, em Mato Grosso do Sul.

${ }^{2}$ Uma rezadora reconhecida por sua competência em tratar o coaio virado comentou que a doença que aparece como uma assimetria na parte superior do corpo também afeta pessoas adultas. Não existe unanimidade, no caso das crianças, em apontar o período de vulnerabilidade ao coaio virado. Todavia, os relatos que ouvi eram descrições de casos, mais frequentemente, em bebês e em crianças na fase de aprender a andar.

${ }^{3}$ A literatura antropológica enfatiza a dualidade da alma entre os Guarani. Além da alma divina, uma outra alma, terrena, vai se desenvolvendo ao longo da vida (Melià etal, 2008). Para uma descrição sobre a relação entre alma divina e nominação ver Mura (2006). Na etnografia de Chamorro (1995) encontra-se ótimo material sobre o assunto.

${ }^{4}$ Vietta (2001) faz uma análise detalhada das articulações políticas em Caarapó a que me refiro como intermedicalidade.

${ }^{5}$ As formas dessa disputa ficam bem explicitadas nos trabalhos de Brand (2004) e Vietta (2007). Há, contudo, um forte componente econômico transnacional no mercado agrícola de Mato Grosso do Sul, especialmente no setor sucroalcooleiro, visando à produção de biocombustíveis, o que não está muito evidenciado no debate atual. 


\section{Referências}

BRAND, Antonio. Os complexos caminhos da luta pela terra entre os Kaiowá e Guarani no MS. Tellus, Campo Grande, n. 6, p. 137-150, abr. 2004.

CADOGAN, Léon. Ayvu Rapyta. Textos Míticos de los Mbyá-Guaraní del Guairá. Assunção: Ceaduc-Cepag, 1997.

. Síntesis de la medicina racional y mística mbyá-guaraní. In:

Tradiciones Guaraníes em el Folklore Paraguayo. Assunção: Fundação León CadoganCepag, 2003.

CHAMORRO, Graciela. Kurusu ñe'ëngatu: palabras que la historia no podria olvidar. Asunción: Ceaduc/Sao Leopoldo:Iepg-Comin, 1995.

CLASTRES, Hélène. Terra sem mal. São Paulo: Brasiliense, 1978.

GREENE, Shane. The shaman's needle: development, shamanic agency, and intermedicality in Aguaruna Lands, Peru. American Ethnologist, n. 25, v. 4, p. 634$658,1998$.

MELIÀ, Bartomeu; GRÜNBERG, Georg; GRÜNBERG, Friedl. Pâ̂-Tavyterã. Etnografía guaraní del Paraguay contemporáneo. Assunção: Ceaduc-Cepag, 2008.

MURA, Fabio. À procura do bom viver: Território, tradição de conhecimento e ecologia doméstica entre os Kaiowa. Tese (Doutorado em Antropologia Social) - PPGASMN/UFRJ, Rio de Janeiro, 2006.

VIETTA, Katya. Tekoha e te'y guasu: algumas considerações sobre articulações políticas Kaiowa e Guarani a partir das noções de parentesco e ocupação espacial. Tellus, Campo Grande, n.1, p. 89-102, out. 2001.

. Histórias sobre terras e xamãs kaiowa: territorialidade e organização social na perspectiva dos Kaiowa de Panambizinho (Dourados, MS) após 170 anos de exploração e povoamento não indígena da faixa de fronteira entre o Brasil e o Paraguai. Tese (Doutorado em Antropologia Social) - PPGAS/USP, São Paulo, 2007.

Recebido em 7 de janeiro de 2009.

Aprovado para publicação em 2 de fevereiro de 2009.

214 Nádia Heusi SILVEIRA. Mitã kambyryru jere - notas sobre uma doença... 